\title{
Research on Bending Rigidity at Flange Connections of UHV Composite Electrical Equipment
}

\author{
Haibo Wang $\mathbb{D}^{1}{ }^{1}$ Yongfeng Cheng, ${ }^{1}$ Zhicheng Lu, ${ }^{1}$ Zhubing Zhu, ${ }^{1}$ and Shujun Zhang ${ }^{2}$ \\ ${ }^{1}$ China Electric Power Research Institute, Beijing 100192, China \\ ${ }^{2}$ State Grid Zhejiang Electric Power CO. LTD, Hangzhou 310007, China \\ Correspondence should be addressed to Haibo Wang; whblywhb@163.com
}

Received 9 September 2019; Accepted 4 February 2020; Published 13 March 2020

Academic Editor: Giuseppe Ruta

Copyright (c) 2020 Haibo Wang et al. This is an open access article distributed under the Creative Commons Attribution License, which permits unrestricted use, distribution, and reproduction in any medium, provided the original work is properly cited.

Pillar electrical equipment is an important part of substations. The application of composite materials in pillar equipment can facilitate the improvement of the seismic performance of electrical equipment. In this paper, the test of elastic modulus and bending rigidity was conducted for individual composite elements in insulators and arresters, and the calculation formula for bending rigidity at the composite flange cementing connections was put forward. The numerical simulation model for the earthquake simulation shaking table test of $\pm 1,100 \mathrm{kV}$ composite pillar insulators was established, in which the bending rigidity value for the flange cementing part was obtained by the test or calculation formula. The numerical simulation results were compared with the earthquake simulation shaking table test results, the dynamic characteristics and seismic response of the model were compared, respectively, the validity of the proposed calculation formula for flange bending rigidity of composite cementing parts was verified, and a convenient and effective means was provided for calculating the seismic performance of composite electrical equipment.

\section{Introduction}

Pillar electrical equipment, such as pillar insulators and arresters, is an important part of electrical equipment in substations. The insulators are the electrical equipment components in the substations used to support the live wires or tubular busbars, accommodate the electrical elements, and provide the insulation distance. The traditional pillar electrical equipment is made of porcelain materials. However, since the porcelain materials are prone to brittle damage or fracture during the earthquakes because of their brittleness, the seismic performance of the equipment is rather low, and the seismic capacity of electrical equipment in substations faces bigger challenges [1-4].

The pillar electrical equipment is generally assembled by individual elements connected by flanges. The bending rigidity of flange cementing points is essential for the seismic analysis of electrical equipment. In the analysis of mechanical properties of electrical equipment, the members such as components and flanges of connecting components shall be considered.
For porcelain bushing components, the most widely used flange connection method is cementing. Domestic and foreign scholars have conducted rather systematic study on the rigidity of cementing between the porcelain bushing and the flange [5-11]. The standards in China and Japan treat the flange connections as elastic connections and provide the calculation formula of flange bending rigidity $[5,6]$. Zhu et al. [7] conducted the bending rigidity test of UHV porcelain bushing components, corrected the bending rigidity coefficient formulas proposed in the standards in China and Japan, and provided the calculation formula for flange bending rigidity suitable to UHV porcelain electrical equipment. Zhang et al. [8] studied the bending rigidity of the connections between the UHV porcelain bushing and the flange, corrected the bending rigidity calculation coefficient, and compared it with the test results. Chen et al. [9] studied the bending rigidity of $500 \mathrm{kV}$ arrester flange points by the finite element method and proposed a modeling method suitable for flange cementing points of $\mathrm{HV}$ electrical equipment. 
With the development of materials science, new glass fiber-reinforced plastics (hereinafter referred to as the "composite"), thanks to their good insulation properties and mechanical properties, have gradually become a substitute material to solve the problem of weak seismic performance of porcelain electrical equipment. In recent years, domestic and foreign scholars have carried out corresponding research on the mechanical properties and seismic performance of composite electrical equipment [11-24]. The representative research is the research on the seismic performance of $\pm 800 \mathrm{kV}$ composite insulators conducted by Cheng et al. [12] through the earthquake simulation shaking table test, during which the displacement, strain, and acceleration responses of key parts of the equipment are obtained, and the comparative analysis was conducted for seismic response of the pillar insulators with and without the brackets. Schiff et al. [13] conducted a shaking table test of composite insulators and studied the nonlinear seismic response of composite insulators under seismic loads. Hirwani et al. [15] investigated the effect of delamination on the free vibration behaviour of the laminated composite curved panels of different geometries (cylindrical, spherical, elliptical, hyperboloid, and flat). The effect of different materials and geometrical parameters including the size, location, and position of the delamination on the free vibration behaviour of the laminated composite shell panel has been analysed numerically and discussed in detail. Kulmani et al. [16] studied the vibration frequencies of the multiwalled carbon nanotube-reinforced polymer composite structure. The specific conclusions were drawn by examining different numerical examples for various structural parameters using the experimental properties. Kumosa [22, 23] conducted the test and numerical simulation research on the cementing points between the composite material and the flange in the insulators and analysed the impact of bonding surface properties and adhesive strength on the cementing capacity. Sheng et al. [24] tested the dynamic characteristics of composite insulators and the bending rigidity of flange connections and pointed out that, since the cementing structure of composite insulators is quite different from that of porcelain insulators, the calculation formula for flange bending rigidity proposed in the standards in China and Japan is no longer applicable to composite equipment.

In conclusion, because of the difference between the cementing structure of flanges in composite equipment and that in porcelain equipment, the calculation formula for bending rigidity at flange connections of porcelain equipment is no longer applicable to the composite equipment. With the wide application of composite equipment, the seismic performance verification of the equipment requires the accurate establishment of the calculation model for bending rigidity at flange connections. At present, there is no in-depth study on the bending rigidity at composite flange connections. In this paper, the test of elastic modulus and bending rigidity was conducted for individual elements in composite insulators and composite arresters, and the calculation formula for bending rigidity at flange connections was obtained by the analysis and research of test data. The methods of numerical simulation and earthquake simulation shaking table test were used to conduct the comparative study on the seismic performance of $\pm 1,100 \mathrm{kV}$ pillar insulators, and the validity of the proposed calculation formula for flange bending rigidity was verified.

\section{Test of Elastic Modulus and Bending Rigidity for Individual Composite Elements}

2.1. Test Pieces. The test pieces are individual elements of the $\pm 1,100 \mathrm{kV}$ pillar insulator and $\pm 800 \mathrm{kV}$ arrester equipment. The $\pm 1,100 \mathrm{kV}$ pillar insulator has a total length of $15.66 \mathrm{~m}$ and a total weight of 3.7 tons. Figure 1(a) illustrates the corresponding assembly diagram. The pillar insulator is assembled from six individual insulators (labeled $A 1, A 2, A 3$, $A 4, A 5$, and $A 6$ from top to bottom), each of which consists of a solid composite insulator pillar with a diameter of $300 \mathrm{~mm}$. Both ends of the insulator pillar are cemented to the flange by adhesive. The $\pm 800 \mathrm{kV}$ arrester has a total length of $6.26 \mathrm{~m}$ and a total weight of 1.23 tons. Figure $1(\mathrm{~b})$ illustrates the corresponding assembly diagram. The arrester is assembled by two composite bushings (labeled $A 7$ and $A 8$ from top to bottom), of which A7 has a length of $3.10 \mathrm{~m}$, an outer diameter of $320 \mathrm{~mm}$, and a wall thickness of $10 \mathrm{~mm}$ and $A 8$ has a length of $3.16 \mathrm{~m}$, an outer diameter of $400 \mathrm{~mm}$, and a wall thickness of $21 \mathrm{~mm}$. Both ends of the bushing are cemented to the flange by adhesive. The parameters of the insulators are shown in Table 1. Figure 1(c) illustrates the parameters of the cementing between the bushing and the flange, where $d$ is the outer diameter for flange cementing and $h$ is the flange height. The unit of length is $\mathrm{mm}$, and the unit of mass is $\mathrm{kg}$.

2.2. Test Scheme. The test principle and scheme for the elastic modulus of individual insulators and the bending rigidity at the insulator flange connections have been introduced in detail in reference [21], so they will not be described in detail here.

Regarding the test of elastic modulus, the stress at the root of the pillar insulator can be calculated by the following formula:

$$
\sigma=\frac{32 F H}{\pi D^{3}},
$$

where $F$ is the tensile force applied on the top end of the pillar insulator by the actuator, $H$ is the height of the top end of the pillar insulator relative to the strain gauge pasting location, and $D$ is the diameter of the pillar insulator.

The bending rigidity of the flange is defined as follows:

$$
K_{c}=\frac{M}{\theta}=\frac{F L}{\theta},
$$

where $M$ is the moment of force applied on the cementing part, $F$ is the tensile force applied on the top end of the insulator, $L$ is the length of the pillar insulator, and $\theta$ is the rotation angle of the cementing part.

2.3. Test Results. Figure 2 illustrates the curves of change of the force applied on the top end of insulators A1 and A6 with 


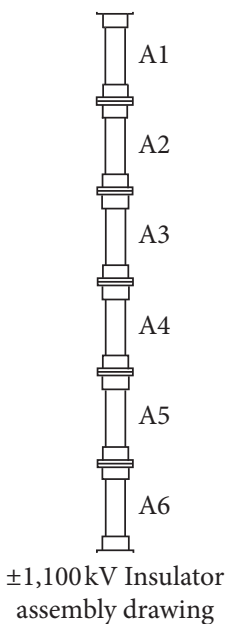

(a)

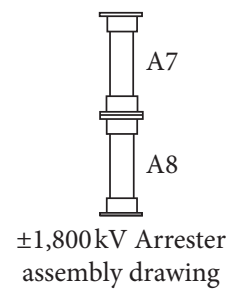

assembly drawing

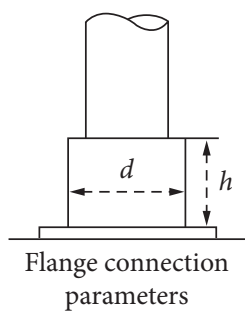

parameters

(b)

(c)

Figure 1: Schematic diagram of the test piece assembly. (a) $\pm 1,100 \mathrm{kV}$ insulator assembly drawing, (b) $\pm 800 \mathrm{kV}$ arrester assembly drawing, (c) flange connection parameters.

TABLE 1: Parameters of individual insulators.

\begin{tabular}{lccccc}
\hline No. & Length & Mass & Diameter of the section & Flange height & Outer diameter of the flange \\
\hline$A 1$ & 3225 & 710 & 300 & 150 & 340 \\
$A 2$ & 2425 & 585 & 300 & 150 & 340 \\
$A 3$ & 2465 & 590 & 300 & 180 & 340 \\
$A 4$ & 2495 & 595 & 300 & 180 & 340 \\
$A 5$ & 2495 & 595 & 300 & 200 & 360 \\
$A 6$ & 2555 & 630 & 300 & 220 & 360 \\
$A 7$ & 3100 & 372 & 320 & 105 & 330 \\
$A 8$ & 3160 & 853 & 400 & 108 & 410 \\
\hline
\end{tabular}

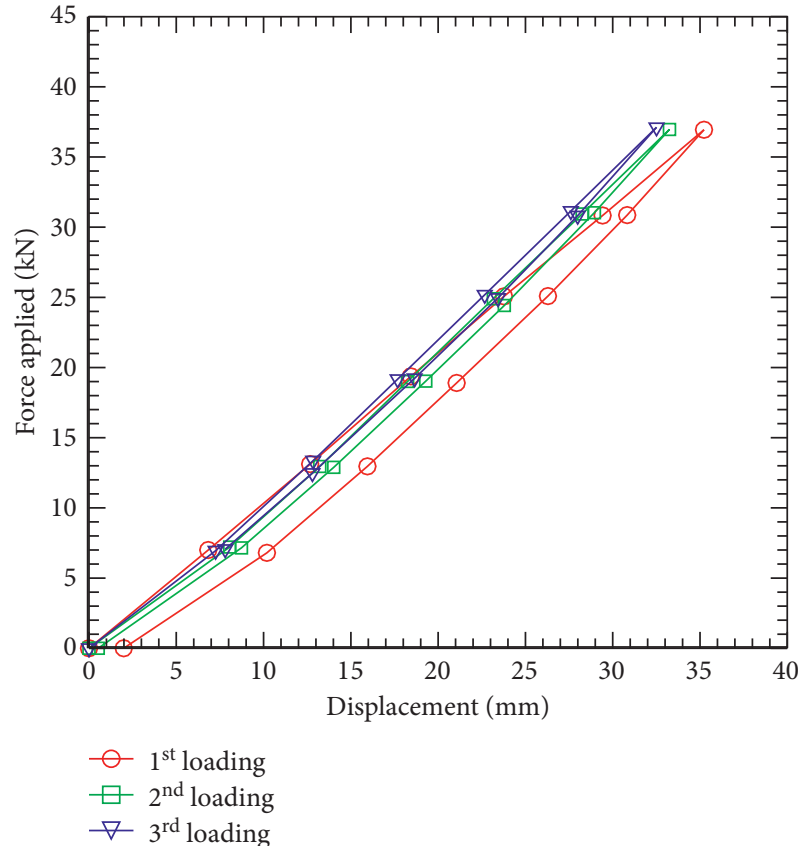

(a)

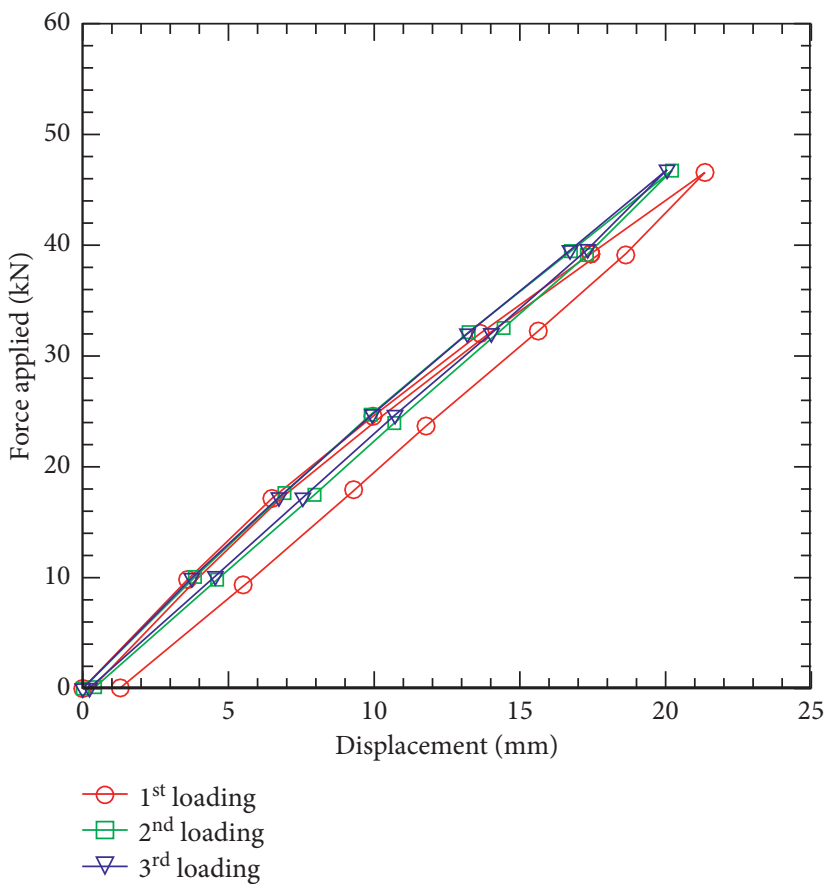

(b)

Figure 2: Curves of change of force applied on the top end of individual insulators $A 1$ (a) and $A 6$ (b) with the displacement of the top end. 
the displacement of the top end. As can be seen from the curves in the figure, the change law of the "load-displacement" relationship of individual insulator elements is basically the same.

Let us take insulator $A 6$ as an example. The elastic modulus on the tension side is about $40.7 \mathrm{GPa}$, and the elastic modulus on the compression side is about $41.2 \mathrm{GPa}$. The linear fitting is performed for the stress data on the tension side and those on the compression side, and the slope of the fitted curve is taken as the average elastic modulus of insulator A6, as illustrated in Figure 3. Table 2 shows the elastic moduli of the remaining seven insulators.

Figure 4 illustrates the curves of the relationship between the bending moment at the root of the insulator and the rotation angle of the flange in insulator $A 6$. The slope of the curve is the bending rigidity of the insulator flange connection. The tensile and compressive bending rigidities are averaged to obtain the bending rigidity of individual insulators. For example, the tensile bending rigidity at the flange cementing part of insulator $A 6$ is about $54,391 \mathrm{kN} \cdot \mathrm{m} /$ $\mathrm{rad}$ and the compressive bending rigidity is about $38,394 \mathrm{kN} \cdot \mathrm{m} / \mathrm{rad}$. The linear fitting is uniformly performed for the test data at the tension side and the compression side, and the slope of the curve is taken as the average bending rigidity of insulator $A 6$. As a result, the average bending rigidity of the flange cementing part of insulator $A 6$ is about $41,377 \mathrm{kN} \cdot \mathrm{m} / \mathrm{rad}$. The bending rigidities of flange cementing parts of remaining insulators are shown in Table 3, in which the unit of bending rigidity is $\mathrm{kN} \cdot \mathrm{m} /$ rad.

\section{Study on Calculation Formula of Flange Bending Rigidity}

For the bending rigidity at flange connections of the porcelain material, the calculation formulas for flange bending rigidity specified in the standards in China and Japan $[5,6]$ are obtained by regression fitting of test data, and they are consistent when they are expressed in international units. The specific calculation formula is as follows:

$$
K_{c}=\frac{\beta d_{c} h_{c}^{2}}{t_{e}},
$$

where $K_{c}$ is the bending rigidity at the connection between flange and equipment, the unit of which is $\mathrm{N} \cdot \mathrm{m} / \mathrm{rad} ; d_{c}$ is the outer diameter of the porcelain bushing at the cementing part, the unit of which is $\mathrm{m} ; h_{c}$ is the flange cementing height, the unit of which is $\mathrm{m} ; t_{e}$ is the cementing clearance between the porcelain bushing and the flange, the unit of which is $\mathrm{m}$; and $\beta$ is the bending rigidity coefficient, the value of which is $6.54 \times 10^{7}$.

The connection between the porcelain bushing and the flange is generally filled with cement mortar, and the cementing thickness is between $5 \mathrm{~mm}$ and $15 \mathrm{~mm}$. However, the connection between the composite insulator bushing and the flange is generally realized by synthetic adhesive. The cementing thickness is rather small, generally smaller than

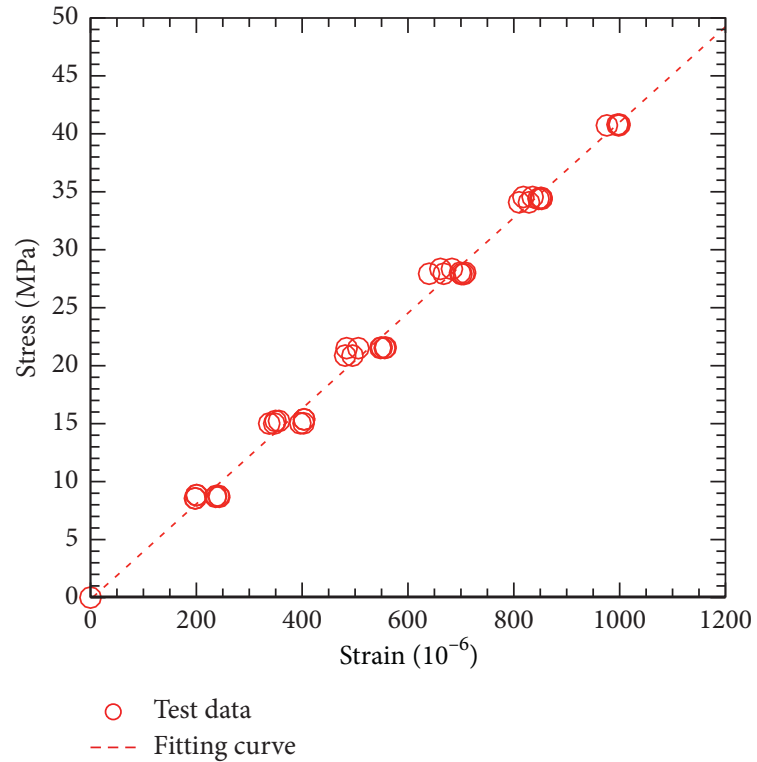

FIgURe 3: Elastic modulus of insulator A6.

TABLe 2: Elastic moduli of individual insulators.

\begin{tabular}{lccc}
\hline Elastic modulus $(\mathrm{GPa})$ & Tensile & Compressive & Average \\
\hline A1 & 71.4 & 66.6 & 68.7 \\
A2 & 66.6 & 64.4 & 65.5 \\
A3 & 75.1 & 62.8 & 67.8 \\
A4 & 67.1 & 92.8 & 75.9 \\
A5 & 49.7 & 47.6 & 48.5 \\
A6 & 40.7 & 41.2 & 40.9 \\
A7 & 20.5 & 20.9 & 20.7 \\
A8 & 14.6 & 12.3 & 13.3 \\
\hline
\end{tabular}

$1 \mathrm{~mm}$. There is a rather large difference between the cementing structure and the porcelain insulator, as illustrated in Figure 5. Therefore, the empirical calculation formula (3) for bending rigidity at flange connections of porcelain material insulators is no longer applicable to composite insulators.

As can be known from the flange height, the outer diameter of the flange and the relation between insulator elastic modulus and bending rigidity at the flange cementing part in individual insulators $A 1$ and $A 2$ have the same geometrical parameter of flanges, and their bending rigidity decreases with the increase of the insulator elastic modulus; $A 3$ has the same outer diameter of the flange and similar insulator elastic modulus as $A 1$ and $A 2$, and its bending rigidity increases with the increase of the flange height; although $A 5$ and $A 6$ have larger flange heights and smaller insulator elastic modulus, the bending rigidity at the flange cementing part is smaller than that of $A 3$ and $A 4$ because they have larger outer diameters of flanges, so the bending rigidity decreases with the increase of the outer diameter of the flange. Assume that the relations between flange bending rigidity $\left(K_{c}\right)$, cementing height $\left(h_{c}\right)$, outer diameter of cementing $\left(d_{c}\right)$, and insulator elastic modulus $(E)$ are as follows: 


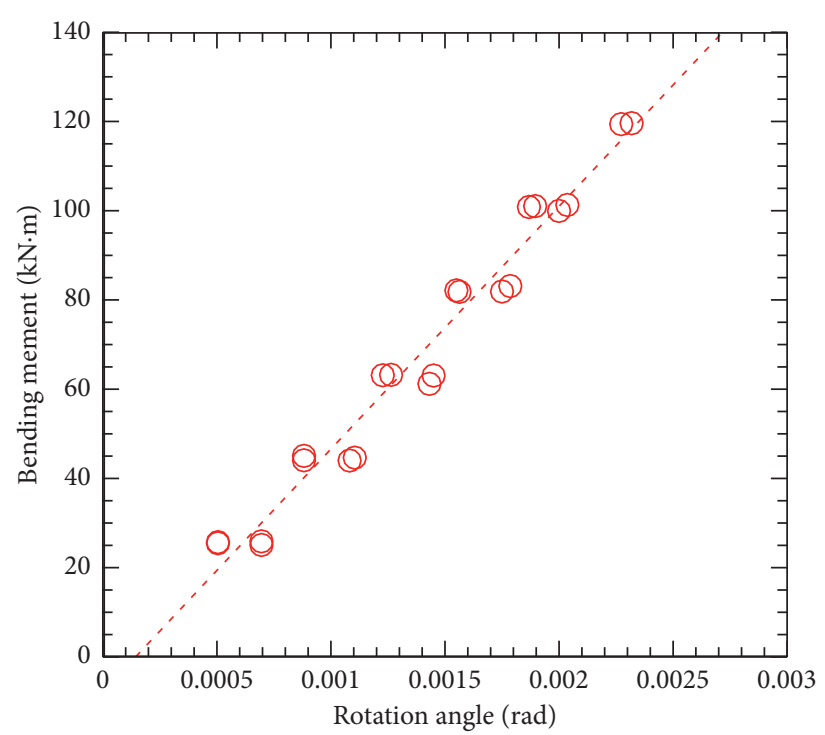

(a)

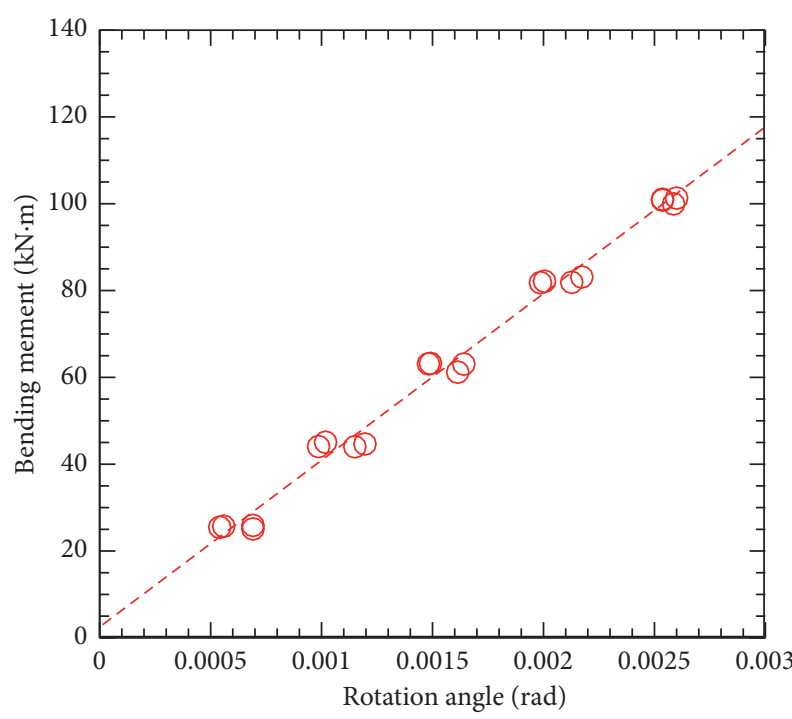

(b)

FIgURE 4: Change of bending moment with the rotation angle in individual insulator A6 at the (a) tension side and (b) compression side.

TABLE 3: Bending rigidities of individual insulators.

\begin{tabular}{lccc}
\hline Bending rigidity & Tensile & Compressive & Average \\
\hline A1 & 37429 & 43845 & 37373 \\
A2 & 36913 & 48242 & 38179 \\
A3 & 48023 & 51218 & 49244 \\
A4 & 42137 & 47482 & 43613 \\
A5 & 37430 & 27716 & 30437 \\
A6 & 54391 & 38394 & 41377 \\
A7 & 16876 & 17136 & 17005 \\
A8 & 28231 & 34961 & 29899 \\
\hline
\end{tabular}

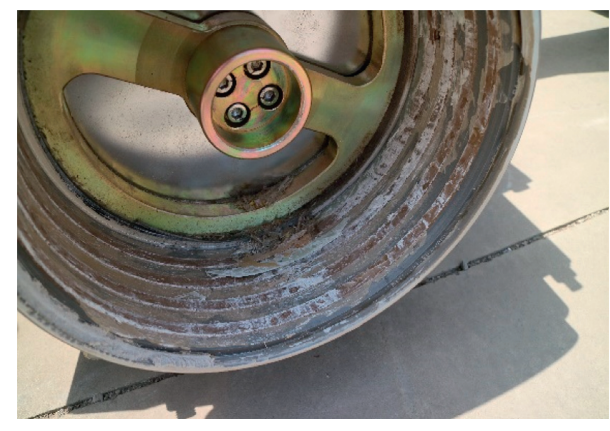

FIGURE 5: Cementing connection of the composite insulator flange.

$$
K_{c}=\lambda_{c} \frac{h_{c}}{d_{c} E}
$$

where $\lambda_{c}$ is the bending rigidity coefficient.

Taking the flange bending rigidity test data of the $\pm 1,100 \mathrm{kV}$ composite pillar insulator and $\pm 800 \mathrm{kV}$ arrester as an example, the relations between various parameters and flange bending rigidity are shown in Table 4 .

As can be known from the above data analysis, when the change of height and outer diameter of flange cementing is not large, the change ranges of the bending rigidity
TABLE 4: Test parameters for flange bending rigidity of composite pillar insulators.

\begin{tabular}{cccccc}
\hline$S / N$ & $h_{c}(\mathrm{~m})$ & $d_{c}(\mathrm{~m})$ & $E(\mathrm{GPa})$ & $K_{c}(\mathrm{~N} . \mathrm{m} / \mathrm{rad})$ & $\lambda_{c}$ \\
\hline$A 1$ & 0.15 & 0.34 & 68.7 & $3.7373 \times 10^{7}$ & $5.8213 \times 10^{18}$ \\
$A 2$ & 0.15 & 0.34 & 65.5 & $3.8179 \times 10^{7}$ & $5.6645 \times 10^{18}$ \\
$A 3$ & 0.18 & 0.34 & 67.8 & $4.9244 \times 10^{7}$ & $6.3052 \times 10^{18}$ \\
$A 4$ & 0.18 & 0.34 & 75.9 & $4.3613 \times 10^{7}$ & $6.2482 \times 10^{18}$ \\
$A 5$ & 0.20 & 0.36 & 48.5 & $3.0437 \times 10^{7}$ & $2.6467 \times 10^{18}$ \\
$A 6$ & 0.22 & 0.36 & 40.9 & $4.1377 \times 10^{7}$ & $2.7769 \times 10^{18}$ \\
$A 7$ & 0.105 & 0.33 & 20.7 & $1.7005 \times 10^{7}$ & $1.1062 \times 10^{18}$ \\
$A 8$ & 0.108 & 0.41 & 13.3 & $2.9899 \times 10^{7}$ & $1.5096 \times 10^{18}$ \\
\hline
\end{tabular}

coefficient and flange bending rigidity are rather large. Assuming that the flange bending rigidity is a relation related to flange bending rigidity, the fitting study is further conducted for the test data. The results show that there is a linear relation between bending rigidity coefficient and insulator elastic modulus, as illustrated in Figure 6.

As can be seen from Figure 6, the flange bending rigidity coefficient $\lambda_{c}$ and the insulator elastic modulus $E$ can be expressed as follows:

$$
\lambda_{c}=9.01 \times 10^{7} E-5.09 \times 10^{17} .
$$

After substituting the bending rigidity coefficient formula (5) into formula (4), we can obtain the relation between the bending rigidity at the flange cementing part in the composite insulator and the flange cementing parameters and insulator elastic modulus, as follows:

$$
K_{c}=\left(9.01 \times 10^{7} E-5.09 \times 10^{17}\right) \frac{h_{c}}{d_{c} E},
$$

where $K_{c}$ is the bending rigidity at the connection between flange and equipment, the unit of which is N.m/rad; $d_{c}$ is the outer diameter of the cementing part of the composite insulator, the unit of which is $\mathrm{m} ; h_{c}$ is the flange cementing 


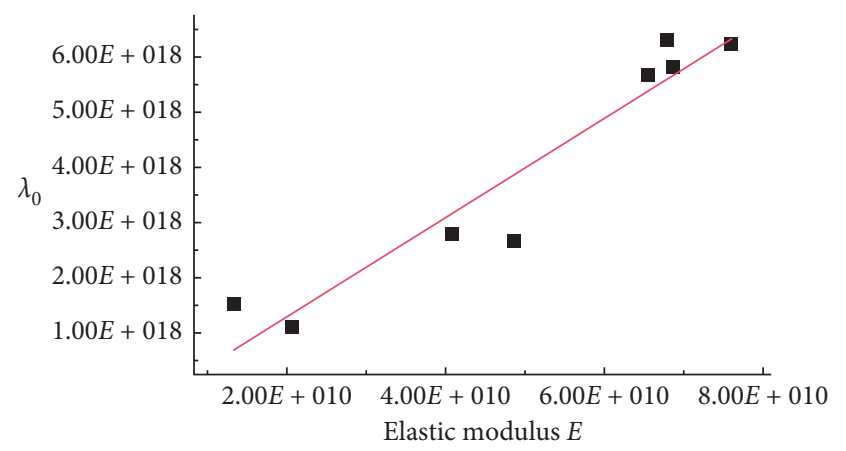

FIGURE 6: Relation between bending rigidity coefficient and elastic modulus.

height, the unit of which is $\mathrm{m}$; and $E$ is the elastic modulus of the composite insulator, the unit of which is $\mathrm{Pa}$.

\section{Verification of Calculation Formula for Flange Bending Rigidity}

The finite element structural analysis software ABAQUS was used to establish a numerical model of $\pm 1,100 \mathrm{kV}$ composite pillar insulators. The insulator bushings and the flanges are simulated by beam elements. The sectional dimensions of beam elements at the flange sections are obtained by bending rigidity to establish the numerical simulation model, and the boundary of the simulation model is that the bottom of the composite pillar insulator is fixed. The calculation model for bending rigidity at flange connections obtained by the test is called Model-1, while the model obtained by calculation formula (6) is called Model-2. The results of such two models are, respectively, compared with the results of the earthquake simulation shaking table test of $\pm 1,100 \mathrm{kV}$ composite pillar insulators to verify the validity of the calculation formula for composite flange bending rigidity.

Reference [22] provides the detailed introduction of the earthquake simulation shaking table test of $\pm 1,100 \mathrm{kV}$ composite pillar insulators, so the test process is not descried here, and only the corresponding test results are listed in this paper.

4.1. Analysis of Dynamic Characteristics' Results. A numerical model of $\pm 1,100 \mathrm{kV}$ composite pillar insulators was established by using the common finite element structural analysis software ABAQUS. The structural dimensions of the insulator bushing are consistent with those used in the test. The elastic modulus values are the average values in Table 2. The diameters of sections (in $\mathrm{mm}$ ) of beam elements in various flanges in Model-1 and Model-2 are shown in Table 5.

The modal analysis of Model-1 and Model-2 is carried out, respectively, and the vibration modes and natural vibration frequencies of the models are obtained, respectively, as illustrated in Figure 7. The comparison between the natural vibration frequencies obtained in the two models and the test results is shown in Table 6.
TABle 5: Model material parameters.

\begin{tabular}{lcc}
\hline Insulator & Model-1 & Model-2 \\
\hline$A 1$ & 201.9 & 200.7 \\
$A 2$ & 205.4 & 202.9 \\
A3 & 227.2 & 220.5 \\
A4 & 214.2 & 214.9 \\
A5 & 224.8 & 246.9 \\
A6 & 259.5 & 268.5 \\
\hline
\end{tabular}

As can be seen from Table 6 , the relative errors of the $1^{\text {st }}$, $2^{\text {nd }}$, and $3^{\text {rd }}$ order frequencies of Model- 1 are $6.3 \%, 1.5 \%$, and $0 \%$, respectively, while those of the $1^{\text {st }}, 2^{\text {nd }}$, and $3^{\text {rd }}$ order frequencies of Model-2 are 3.2\%, $1.8 \%$, and $0.8 \%$, respectively. It can be seen from this that Model- 2 can better reflect the natural vibration frequency of the true model.

4.2. Analysis of Seismic Response Results. In order to check the seismic performance of $\pm 1,100 \mathrm{kV}$ composite pillar insulators, it is necessary to carry out the shaking table test or numerical simulation research. The reasonable simplification of flange connections in the numerical simulation model is very important. In order to further verify the validity of calculation formula (6) for flange bending rigidity, the time-history analysis is conducted for Model-1 and Model-2, respectively, and the numerical simulation results are compared with the shaking table test results.

The test results of $\pm 1,100 \mathrm{kV}$ composite pillar insulators under artificial waves can be obtained from reference [21]. The shaking table test is illustrated in Figure 8. The relative displacement of the top end of the insulator, the relative acceleration of the top end of the insulator, and the maximum stress at the root of the insulator are obtained by the shaking table test, as shown in Table 7:

The input seismic waves for numerical simulation and test models were determined by China Electric Power Research Institute and China Earthquake Disaster Prevention Center according to the particularity of UHV projects, and the corresponding seismic design response spectrum curve was developed. The characteristic cycle of the curve is $0.9 \mathrm{~s}$, and the dynamic amplification factor is 3.17 (2\% damping ratio) [23-25]. The artificial waves at the peak acceleration of $1.0 \mathrm{~g}$ are illustrated in Figure 9. When the test input is the seismic wave excitations under different intensity levels, the seismic waves in Figure 9 are zoomed in or out according to the ratio.

The artificial waves at $0.1 \mathrm{~g}, 0.2 \mathrm{~g}, 0.3 \mathrm{~g}$, and $0.4 \mathrm{~g}$ were selected, respectively, and the $X$-direction unidirectional loading was carried out on the numerical simulation model. The time-history curves of the stress at the root of the bushing and those of relative displacement at the top end of the bushing were obtained, as illustrated in Figures 10 and 11 , respectively.

As can be seen from Figure 10, for the artificial waves at $0.1 \mathrm{~g}$ input into the numerical simulation model, the maximum stresses at the root of the insulator in Model-1 and Model-2 are $9.48 \mathrm{MPa}$ and $9.39 \mathrm{MPa}$, respectively; for the artificial waves at $0.2 \mathrm{~g}$, the maximum stresses at the root of 


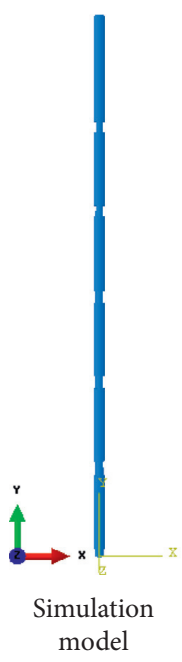

(a)

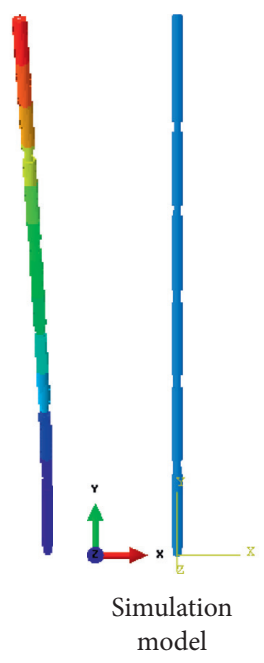

(b)

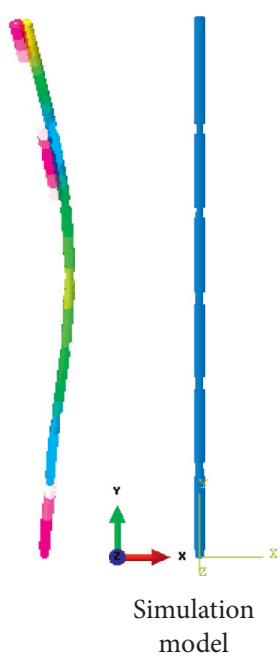

(c)

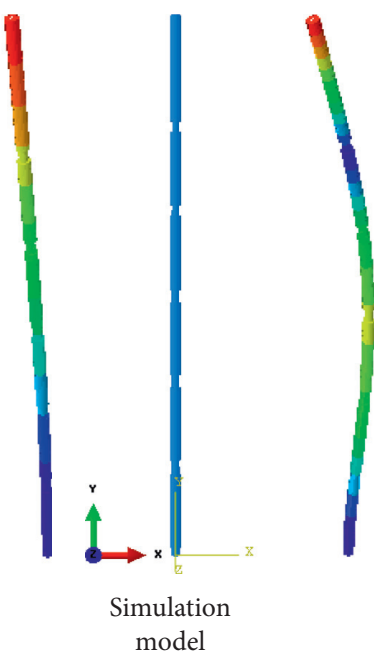

(d)

Figure 7: Vibration mode of the numerical simulation model. (a) Model-1, $1^{\text {st }}$ order vibration mode $f=0.59 \mathrm{~Hz}$. (b) Model-1, $2^{\text {nd }}$ order vibration mode $f=3.96 \mathrm{~Hz}$. (c) Model $-1,1^{\text {st }}$ order vibration mode $f=0.61 \mathrm{~Hz}$. (d) Model-2, $2^{\text {nd }}$ order vibration mode $f=3.97 \mathrm{~Hz}$.

TABLE 6: Comparison of natural vibration frequencies of models.

\begin{tabular}{lccc}
\hline Vibration mode & 1 & 2 & 3 \\
\hline Test value $(\mathrm{Hz})$ & 0.63 & 3.90 & 10.75 \\
Model-1 $(\mathrm{Hz})$ & 0.59 & 3.96 & 10.75 \\
Model-2 $(\mathrm{Hz})$ & 0.61 & 3.97 & 10.84 \\
\hline
\end{tabular}

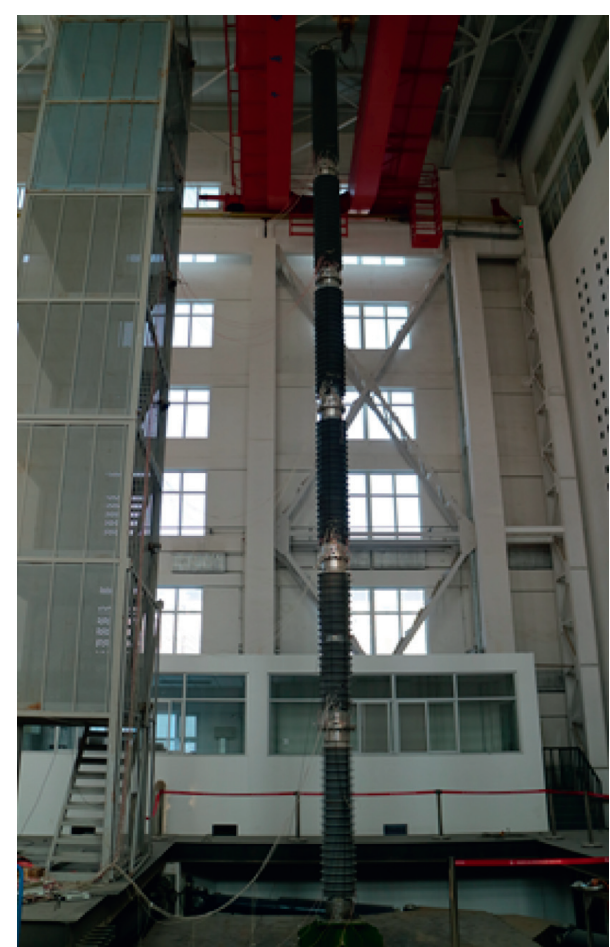

FIgURE 8: Shaking table test of $\pm 1,100 \mathrm{kV}$ composite pillar insulators.

the insulator in Model-1 and Model-2 are 15.48 $\mathrm{MPa}$ and 15.72 $\mathrm{MPa}$, respectively; for the artificial waves at $0.3 \mathrm{~g}$, the maximum stresses at the root of the insulator in Model-1
TABLE 7: Shaking table test results of $\pm 1,100 \mathrm{kV}$ composite pillar insulators.

\begin{tabular}{lcc}
\hline $\begin{array}{l}\text { Artificial wave } \\
(\mathrm{g})\end{array}$ & $\begin{array}{c}\text { Relative displacement of the top } \\
\text { end }(\mathrm{mm})\end{array}$ & $\begin{array}{c}\text { Root stress } \\
(\mathrm{MPa})\end{array}$ \\
\hline 0.1 & 187.9 & 11.40 \\
0.2 & 371.8 & 17.84 \\
0.3 & 532.2 & 24.51 \\
0.4 & 682.3 & 29.37 \\
\hline
\end{tabular}

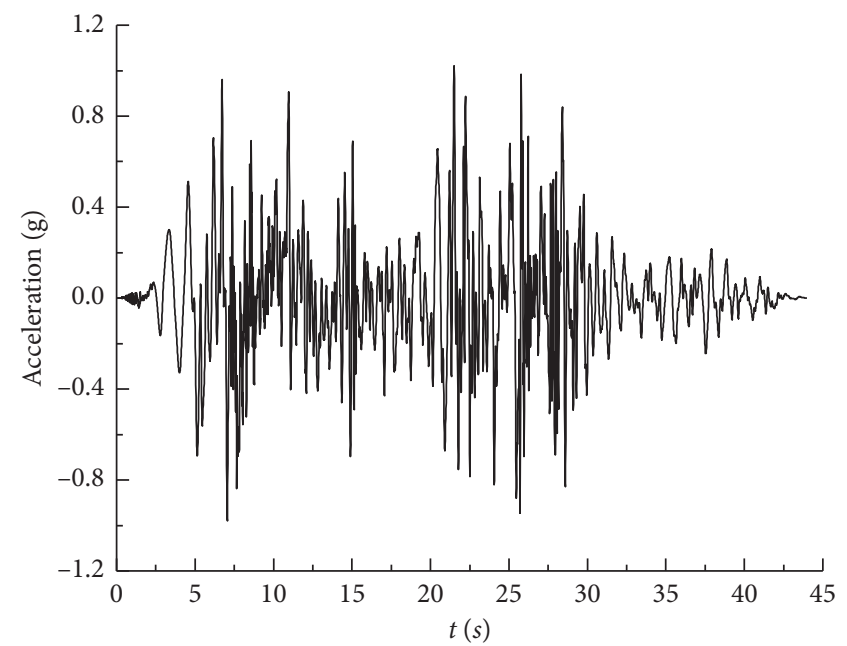

Figure 9: Input seismic waves.

and Model-2 are 9.48 $\mathrm{MPa}$ and 9.39 $\mathrm{MPa}$, respectively; and for the artificial waves at $0.4 \mathrm{~g}$, the maximum stresses at the root of the insulator in Model-1 and Model-2 are $31.63 \mathrm{MPa}$ and $32.16 \mathrm{MPa}$, respectively. The results of maximum stresses at the root of the insulator obtained by Model-1 and Model-2 are rather consistent, so the results of bending rigidity for flange cementing parts of insulators in the numerical simulation model obtained by calculation formula 


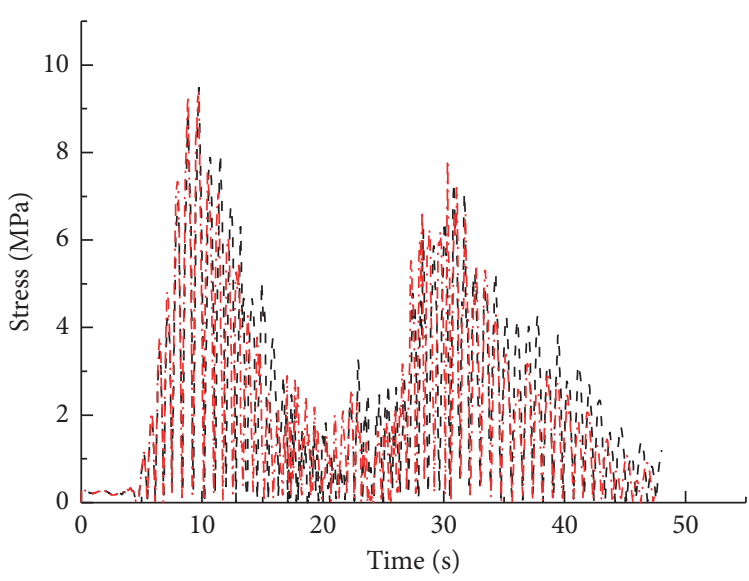

- Model-1

-... Model-2

(a)

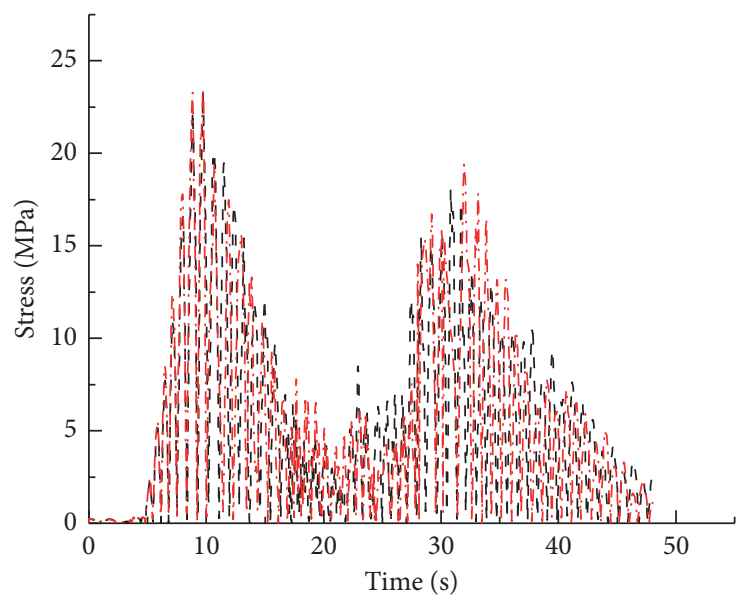

- Model-1

-... Model-2

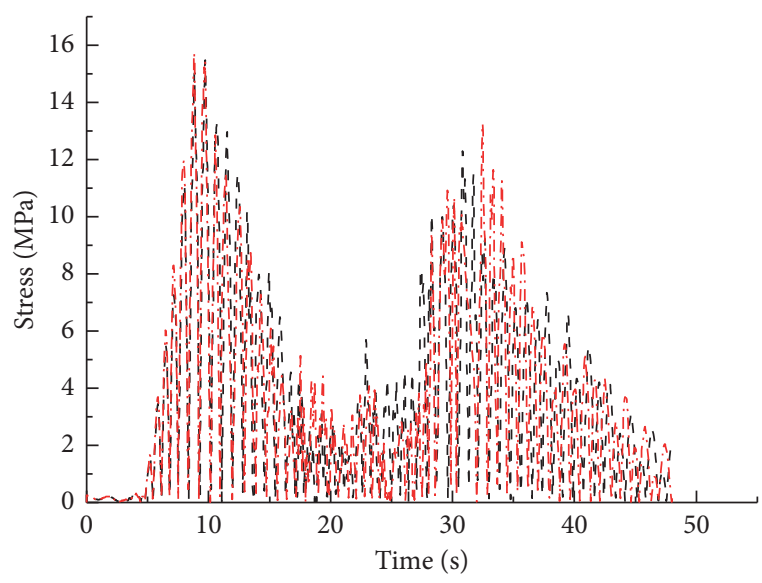

- Model-1

-... Model-2

(b)

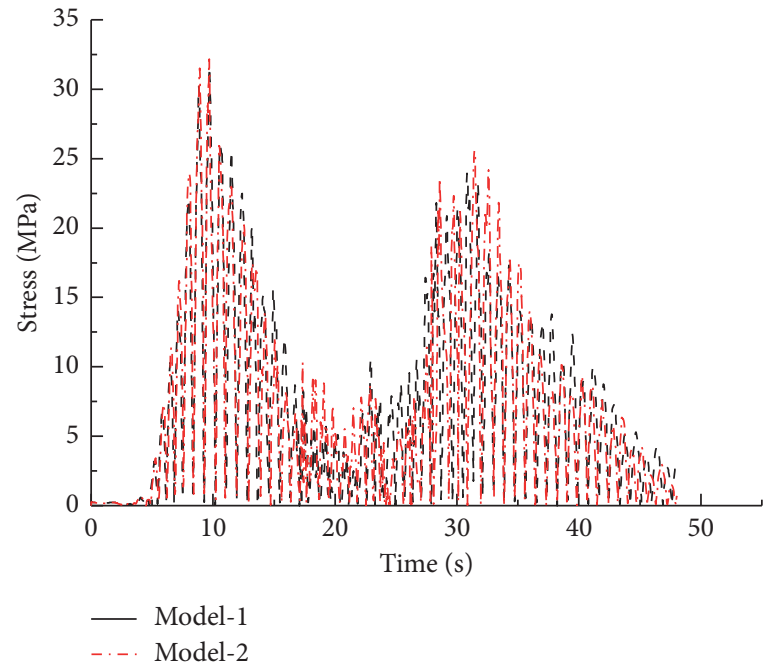

(d)

FIGURE 10: Time-history curves of stresses at the root of the insulator. Maximum stress at the root of insulator at (a) $0.1 \mathrm{~g}$, (b) $0.2 \mathrm{~g}$, (c) $0.3 \mathrm{~g}$, and (d) $0.4 \mathrm{~g}$.

(6) and the results obtained by the bending rigidity test match well with each other.

Next, the relative displacement of the top end of the insulator is further evaluated. As can be seen from Figure 11 and Table 9, for the artificial waves at $0.1 \mathrm{~g}$, the maximum relative displacements of the top end of the insulator in Model-1 and Model-2 are $170.6 \mathrm{~mm}$ and $171.0 \mathrm{~mm}$, respectively; for the artificial waves at $0.2 \mathrm{~g}$, the maximum relative displacements of the top end of the insulator in Model- 1 and Model-2 are $341.2 \mathrm{~mm}$ and $342.0 \mathrm{~mm}$, respectively; for the artificial waves at $0.3 \mathrm{~g}$, the maximum relative displacements of the top end of the insulator in Model- 1 and Model-2 are $518.3 \mathrm{~mm}$ and $520.0 \mathrm{~mm}$, respectively; and for the artificial waves at $0.4 \mathrm{~g}$, the maximum relative displacements of the top end of the insulator in Model-1 and Model-2 are $713.8 \mathrm{~mm}$ and $717.6 \mathrm{~mm}$, respectively. The results of the maximum relative displacements of the top end of the insulator in Model- 1 and Model2 are rather consistent, further indicating that the difference between the results of bending rigidity for flange cementing parts of insulators obtained by calculation formula (6) and the results obtained by the bending rigidity test can be ignored.

Next, the shaking table test results of $\pm 1,100 \mathrm{kV}$ composite pillar insulators are compared with the numerical simulation results. Table 8 shows the peak stress at the root of the insulator, in which the unit is MPa. Table 9 shows the peak relative displacement of the top end of the insulator, in which the unit is $\mathrm{mm}$.

As can be seen from Tables 8 and 9, the range of error between the maximum stress at the root of the insulator in Model- 1 and the test results is $4.5 \%-14.2 \%$ and the range of error in maximum relative displacement at the top end is $2.6 \%-9.2 \%$; the range of error between the maximum stress at the root of the insulator in Model-2 and the test results is $4.4 \%-15.0 \%$, and the range of error in maximum relative displacement at the top end is $2.3 \%-8.9 \%$. Therefore, the numerical simulation model established by using the rigidity 


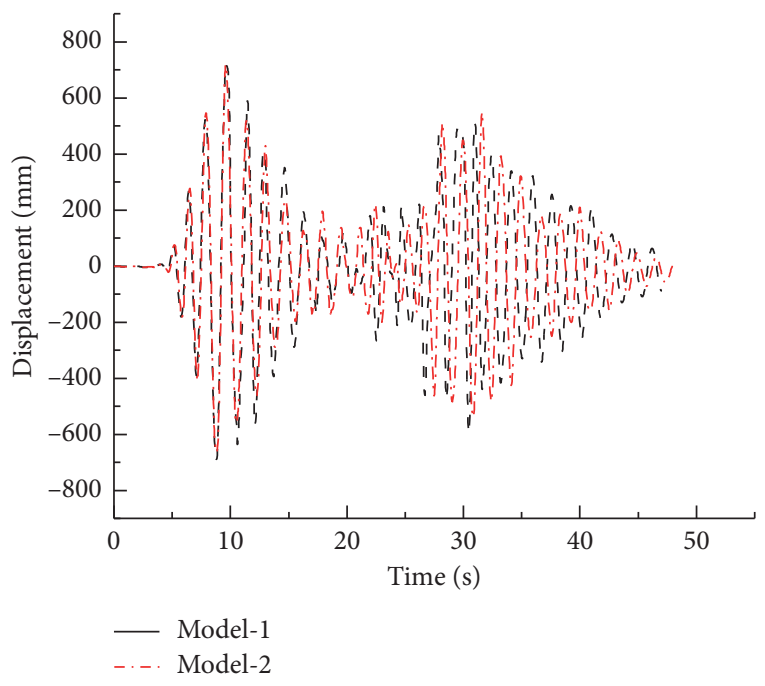

Figure 11: Time-history curves of relative displacement of the top end of the insulator at $0.4 \mathrm{~g}$.

TABLE 8: Comparison of peak stresses at the root of the bushing obtained by the test and simulation.

\begin{tabular}{lccc}
\hline Artificial wave & Test & Model-1 & Model-2 \\
\hline 0.1 & 11.40 & 9.78 & 9.69 \\
0.2 & 17.84 & 15.48 & 15.72 \\
0.3 & 24.51 & 23.39 & 23.42 \\
0.4 & 29.37 & 31.63 & 32.16 \\
\hline
\end{tabular}

TABLE 9: Comparison of peak relative displacements of the top end of the bushing obtained by the test and simulation.

\begin{tabular}{lccc}
\hline Artificial wave $(\mathrm{g})$ & Test & Model-1 & Model-2 \\
\hline 0.1 & 187.9 & 170.6 & 171.0 \\
0.2 & 371.8 & 341.2 & 342.0 \\
0.3 & 532.2 & 518.3 & 520.0 \\
0.4 & 682.3 & 713.8 & 717.6 \\
\hline
\end{tabular}

of the flange cementing part of the insulator obtained by calculation formula (6) is accurate and valid. Since the test of bending rigidity of the flange cementing parts in the individual insulator is omitted, a convenient and effective means is provided for calculating the seismic performance of composite insulators.

\section{Conclusions}

(1) As can be seen from the test of elastic modulus and flange bending rigidity of individual composite pillar insulators, the elastic modulus distribution of individual insulators is relatively discrete, and the average elastic modulus of the selected 8 insulators is 13.3 GPa-75.9 GPa. Therefore, it is advisable to define the elastic modulus of each insulator separately when establishing the numerical model of the $\pm 1,100 \mathrm{kV}$ pillar insulators. The bending rigidities of flange cementing parts of individual insulators are quite different. The bending rigidity of the flange in insulator A5 in the $\pm 1,100 \mathrm{kV}$ pillar insulator is the smallest, while the bending rigidity of the flange in insulator A7 in the $\pm 800 \mathrm{kV}$ arrester is the smallest. Such two flange parts are the weak parts of the pillar insulator.

(2) According to the test of elastic modulus and flange bending rigidity of individual composite pillar insulators, and based on the obtained elastic modulus and flange bending rigidity of individual insulators, the calculation formula for bending rigidity at flange cementing parts of composite insulators is obtained. The formula is related to the elastic modulus of each insulator, the cementing height of the flange cementing part, and the cementing radius.

(3) The numerical simulation models are established, respectively. The calculation model for bending rigidity at flange connections obtained by the test is called Model-1, while the model obtained by calculation formula (6) is called Model-2. The results of such two models are, respectively, compared with the results of the earthquake simulation shaking table test of $\pm 1,100 \mathrm{kV}$ composite pillar insulators. As can be seen from the comparison of dynamic characteristics' results and seismic response results, the calculation formula of composite flange bending rigidity proposed in this paper is accurate and effective. A convenient and effective means is provided for calculating the seismic performance of composite insulators.

\section{Data Availability}

The data used to support the findings of this study are available from the corresponding author upon request.

\section{Conflicts of Interest}

The authors declare that there are no conflicts of interest regarding the publication of this paper.

\section{Acknowledgments}

This study was funded by the Scientific Research Program of SGCC: Research on Seismic Technology of UHV Transformer Based on Soil-Structure Dynamic Interaction (Grant no. 521104180015).

\section{References}

[1] Y. Cheng, Q. Zhu, and Z. Lu, "Progress and development trend on Seismic measures of electric power equipments in transformer substation," Power System Technology, vol. 32, no. 22, pp. 84-89, 2008.

[2] J. Liu, Y. Wang, and W. Han, "Review on seismic disaster analysis and aseismic measures of transformer substation," Electric Power Construction, vol. 32, no. 7, pp. 44-50, 2011.

[3] Z. Guan, G. Peng, L. Wang et al., "Application and key technical study of composite insulators," High Voltage Engineering, vol. 37, no. 3, pp. 513-519, 2011. 
[4] S. Yang and J. Zhao, "An overview on prevention technology of earthquake disaster for power grids," Power System Technology, vol. 34, no. 8, pp. 57-63, 2010.

[5] JEAG 5003-2010, Guide for Seismic Design of Electrical Equipment in Substation [S], Power Generation and Transformation Technical Committee of the Japan Electric Association, Tokyo, Japan, 2010.

[6] Ministry of Housing and Urban-Rural Development of the People's Republic of China, GB 50260-2013: Code for Seismic Design of Electrical Installations [S], China Planning Press, Beijing, China, 2013.

[7] Z. Zhu, Z. Dai, Z. Lu et al., "Experimental study of the bending rigidity at flange connection of UHV electrical equipment," Electric Power, vol. 47, no. 6, pp. 6-11, 2014.

[8] X. Zhang, Z. Dai, M. Cao et al., "Coefficient for calculation of bending stiffness of interconnected parts between ultra-high voltage porcelain bushings and flanges," Engineering Journal of Wuhan University, vol. 47, no. 6, pp. 794-799, 2014.

[9] W. Chen, R. Fan, M. Cao et al., "Study of equivalent bending stiffness of adhesive binding flange joints for post insulator used in high-voltage electric equipment," Insulators and Surge Arresters, vol. 5, no. 273, pp. 7-13, 2016.

[10] A. S. Gilani, A. S. Whittaker, and G. L. Fenves, "Seismic evaluation and retrofit of $230-\mathrm{kV}$ porcelain transformer bushings," Earthquake Spectra, vol. 17, no. 4, pp. 597-616, 2001.

[11] A. S. Gilani, A. S. Whittaker, G. L. Fenves, and E. Fujisaki, Seismic Evaluation of 550-kV Porcelain Transformer bushing [R], Pacific Earthquake Engineering Research Center, Berkeley, California, USA, 1999.

[12] Y. Cheng, Z. Liu, Z. Lu et al., "Experimental study on seismic performance and structural characteristics of $\pm 800 \mathrm{kV}$ composite post insulators," Electric Power, vol. 50, no. 10, pp. 89-96, 2017.

[13] A. J. Schiff and K. Leon, "IEEE693 seismic qualification of composite for substation high-voltage equipment," in Proceedings of the World Conference on Earthquake Engineering, Vancouver, B C, Canada, August 2004.

[14] I. Negru, G. R. Gillich, Z. I. Praisach et al., "Nondestructive evaluation of piers," in Proceedings of the Health Monitoring of Structural and Biological Systems 2015, International Society for Optics and Photonics, San Diego, CA, USA, May 2015.

[15] C. K. Hirwani, R. K. Patil, S. K. Panda et al., "Experimental and numerical analysis of free vibration of delaminated curved panel," Aerospace Science and Technology, vol. 54, pp. 353-370, 2016.

[16] M. Kulmani, K. P. Subrata, and R. M. Trupti, "Theoretical and experimental investigation of vibration characteristic of carbon nanotube reinforced polymer composite structure," International Journal of Mechanical Sciences, vol. 133, pp. 319-329, 2017.

[17] S. S. Sahoo, S. K. Panda, and V. K. Singh, "Experimental and numerical investigation of static and free vibration responses of woven glass/epoxy laminated composite plate," Proceedings of the Institution of Mechanical Engineers, Part L: Journal of Materials: Design and Applications, vol. 231, no. 5, pp. 463478, 2017.

[18] R. Hwasung, D. Nicholas, and M. Andrei, "Experimental test and modeling of hollow-core composite insulators," Nonlinear Dynamics, vol. 69, no. 4, pp. 1651-1663, 2012.

[19] B. Philippe, G. Thomas, and B. John, "Stress and damage analysis of composite aluminium joints used in electrical insulators subject to traction and bending," Composite Structures, vol. 64, no. 3, pp. 359-367, 2004.
[20] B. Anurag, Finite Element Simulation and Mechanical Characterization of Composite insulator [D], Oregon Institute of Science \& Technology, Oregon OR, USA, 1996.

[21] P. Alain, G. Thomas, B. John et al., "Stress and failure analysis of crimped metal-composite joints used in electrical insulators subjected to bending," Composites Part A: Applied Science and Manufacturing, vol. 40, no. 1, pp. 644-652, 2009.

[22] L. S. Kumosa, M. S. Kumosa, and D. L. Armentrout, "Resistance to brittle fracture of glass reinforced polymer composites used in composite (nonceramic) insulators," IEEE Transactions on Power Delivery, vol. 20, no. 4, pp. 2657-2666, 2005.

[23] L. Kumosa, D. Armentrout, and M. Kumosa, “An evaluation of the critical conditions for the initiation of stress corrosion cracking in unidirectional e-glass/polymer composites," Composites Science and Technology, vol. 61, no. 4, pp. 615-623, 2001.

[24] L Sheng, Z. Lu, Z. Zhu, L. Sheng, Z.-B. Zhu, and X.-L. Liu, "Dynamic properties and seismic fragility of substation composite insulators," Engineering Mechanics, vol. 33, no. 4, pp. 91-97, 2016.

[25] H. Liu, Y. Cheng, Z. Lu et al., "Shaking table test of a $\pm 1,100$ $\mathrm{kV}$ composite post insulator," Insulators and Surge Arresters, no. 6, pp. 138-144, 2018. 